\title{
MAKALAH
}

\section{PERINTAH MENGELUARKAN ZAKAT}

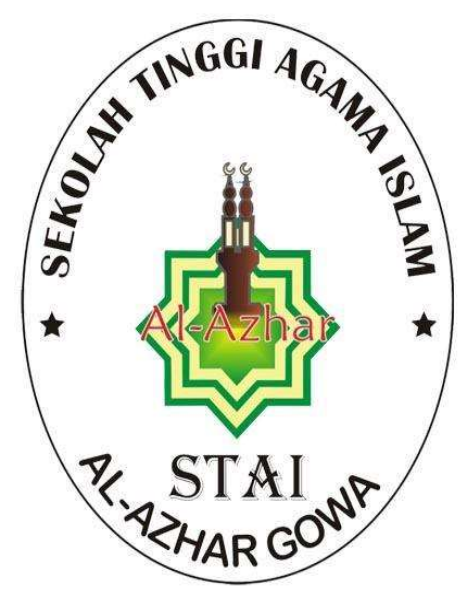

Disusun untuk memenuhi tugas Fiqh Zakat Dan Wakaf

Dosen Pengampu: Samsul Arifai, S.A.B., MA,

Oleh:

MUTATOHHIR

1122020004

\section{EKONOMI SYARIAH}

SEKOLAH TINGGI AGAMA ISLAM

(STAI) AL-AZHAR GOWA

2021 


\section{KATA PENGANTAR}

Puji Syukur Kehadirat Tuhan Yang Maha Esa yang telah melimpahkan rahmat-Nya berupa kesehatan dan kesempatan sehingga makalah ini dapat tersusun sampai selesai.

Penulis berharap semoga makalah ini dapat menambah pengetahuan dan pemahaman para pembaca. Bahkan kami berharap lebih jauh lagi agar makalah ini dapat di praktekkan dalam kehidupan kita baik bagi penulis maupun para pembaca sehingga dapat menjadi amal sholeh bagi kita semua.

Kami sebagai penyusun merasa bahwa masih banyak kekurangan dalam penyusunan makalah ini, olehnya itu kritik dan saran selalu diharapkan dari pembaca terutama dari dosen pembina mata kuliah kami ini.

Sekian dan Terima Kasih.

Makassar, 13 November 2021

Mutatohhir 


\section{DAFTAR ISI}

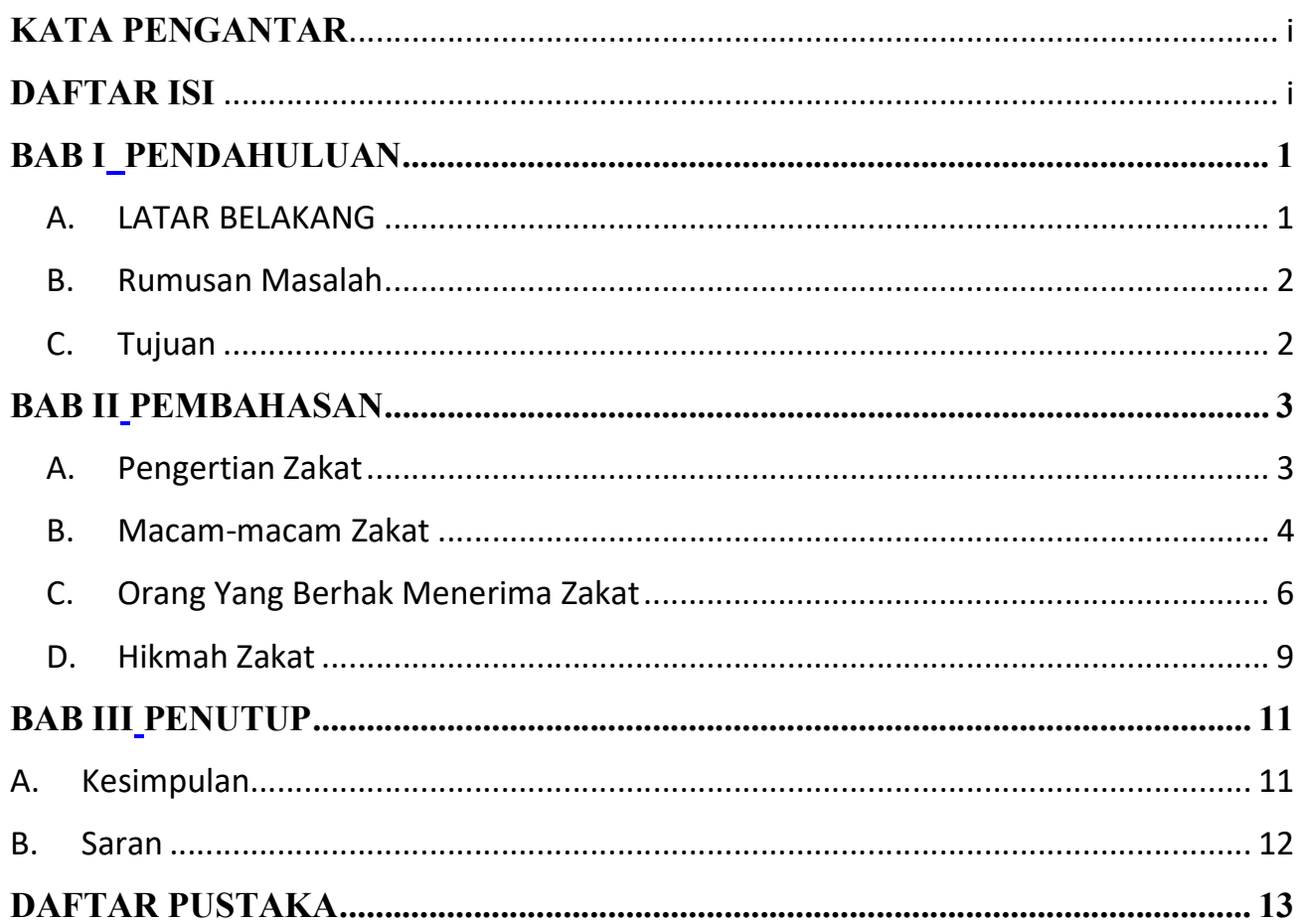




\section{BAB I}

\section{PENDAHULUAN}

\section{A. LATAR BELAKANG}

Zakat dalam ajaran islam mempunyai potensi yang dapat di gunakan sebagai sumber dana untuk memberdayakan umat karena ibadah zakat selain mempunyai dimensi vertikal menjadi bentuk pengabdian kepada sang Kholik, juga memiliki dimensi horizontal menjadi bentuk kepedulian terhadap sesama manusia terutama yang kurang beruntung hidupnya. Zakat adalah kewajiban agama yang dibebankan atas harta kekayaan seseorang menurut aturan tertentu.

Dalam memenuhi kebutuhan hidup, manusia dituntun agar selalu bekerja keras dan berusaha semaksimal mungkin untuk meningkatkan perekonomiannya. Kerena didalam agama islam tidak menghendaki umatnya berada dalam ketertinggalan dan keterbalakangan pada sektor ekonomi yang bisa menjerumuskan manusia kepada kemurtadan dan kekufuran. Maka seorang muslim tidak boleh melaksanakan pekerjaan dengan hanya sekedar untuk memenuhi kebutuhan hidup semata, akan tetapi kita harus melihat semua itu sebagai suatu panggilan dan keharusan agama yang menjadi bagian dari ibadah.

Anjuran kepada suatu usaha ini harus di sertai dengan pendampingan dan bantuan permodalam untuk memulai atau mengembangkan usaha tersebut yaitu melalui pemanfaatan dana zakat untuk pemberdayaan ekonomi umat, pemamfaatannya selain untuk kebutuhan konsumtif bagi masyarakat yang sangat menbutuhkan untuk kelangsungan hidupnya, juga perlu lebih fokus untuk membangun landasan ekonomi umat melalui usaha-usaha produktif. 


\section{B. Rumusan Masalah}

Faedah dan Berdasarkan latar belakang di atas, dapat dirumuskan masalah dari makalah ini adalah:

2. Apa pengertian zakat?

3. Apa saja macam-macam zakat?

4. Siapa saja yang berhak menerima zakat?

5. Apa saja hikmah zakat?

C. Tujuan

Berdasarkan rumusan masalah di atas, maka tujuan penulisan makalah ini adalah:

1. Mengetahui dan memahami pengertian zakat.

2. Mengetahui macam-macam zakat.

3. Mengetahui siapa yang berhak menerima zakat.

4. Mengetahui hikmah zakat. 


\section{BAB II \\ PEMBAHASAN}

\section{A. Pengertian Zakat}

Dalam bahasa arab kata zakat berarti bersih, tumbuh, berkah dan terpuji semua digunakan dalam al-quran dan hadis. Berdasarkan makna-makna tersebut Yusuf Qardawi menyebutkan bahwa arti yang terkuat menurut wahidi dan lain-lain, kata dasar zaka berarti bertambah dan tumbuh sehingga dapat dikatakan tanaman itu zaka artinya tumbuh sedangkan setiap sesuatu yang bertambah di sebut zaka artinya bertambah. Bila suatu tanaman tumbuh tanpa cacat maka di sebut zaka artinya bersih. Adapun dalam pembahasan fikih, istilah zakat diartikan sebagai sejumlah harta tertentu yang di wajibkan Allah untuk dikeluarkan dan diserahkan kepada orang-orang yang berhak menerimanya. Jumlah yang di keluarkan dari kekayaan itu di sebut zakat karna yang di keluarlan itu menambah banyak, mmembuatlebih berarti dan membuat kekayaan itu bebas dari kebinasaan, demikian nanawi mengutip pendapat wahidi. ${ }^{1}$

Ibnu taimiyah berkata: "jiwa orang yang berzakat itu menjadi bersih dan kekayaannya akan bersih pula Makna dari jiwa yang bersih adalah bersih dari penyakit hati bahagia dan merasa tenang sedangkan kekayaannya akan bersih makananya akan bertambah. ${ }^{2}$ Dalam Al-quran surah at-taubah jelas bahwa tujuan zakat itu Mensucikan dan membersihkan itu tidak berfungsi pada kekayaan saja, tetapi lebih dari itu, juga buat jiwa yang menzkaatkannya, sesua dengan firman Allah:

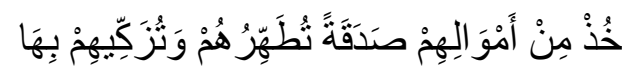

“Ambillah zakat dari harta mereka, guna membersihkan dan menyucikan mereka,"

\footnotetext{
${ }^{1}$ Yusuf Qordowi, Hukum Zakat (Bogor: PT. Pustaka Mizan, 1988).

${ }^{2}$ Yusuf Qordowi.
} 


\section{B. Macam-macam Zakat}

1. Zakat fitrah

a. Makna zakat fitrah

Zakat fitrah merupakan sarana untuk mensucikan orang yang berpuasa dari ucapan kotor dan perbuatan yang tidak berguna, dengan cara menyalurkan sebahagian hartanya orang-orang miskin untuk mencukupi kebutuhan mereka dan agar mereka selamat dari minta-minta pada hari raya. Zakat fitrah merupakan 'pajak' pada pribadi-pribadi muslim, sedangkan zakat lain merupakan pajak pada harta. Karenanya, tidak disyaratkan pada zakat fitrah, apa yang disyaratkan pada zakatzakat lain, seperti memiliki nisab, dengan syarat-syaratnya yang lain. Para Fuqara' menyebutkan zakat ini dengan zakat kepala (perkepala). Yang dimaksud kepala di sini adalah pribadi-pribadi. ${ }^{3}$

b. Hukum zakat fitrah

Zakat adalah salah satu rukun Islam dan menjadi salah satu bagian penting bagi penegakan syariat Islam. Oleh Karna itu, hukum menunaikan zakat adalah wajib bagi setiap individu yang telah memenuhi syarat-syarat sebagai berikut:

1) Islam

Sesuai dengan kesepakatan ulama zakat tidak di wajibkan bagi orang kafir karna zakat merupakan ibadah mahdah yang suci sedangkan orang kafir tidak termasuk orang yang suci.

2) Merdeka

Menurut ahli fiqh dan ijma' zakat tidak diwajibkan bagi hamba sahaya karna secara hukum mereka tidak memiliki hak kepunyaan, tidak memiliki harta karna diri mereka sendiri di anggap sebagai harta.

Adapun anak yang belum baligh dan orang gila jika ia memiliki harta dan memenuhi syarat-syaratnya maka tetap dikenai kewajiban zakat yang nanti akan

\footnotetext{
${ }^{3}$ Kementrian Agama RI, Panduan Zakat Praktis (Jakarta, 2013).
} 
dikeluarkan oleh walinya. Kebanyakan ulama menganggap dan memilih pendapat ini yang terkuat. ${ }^{4}$

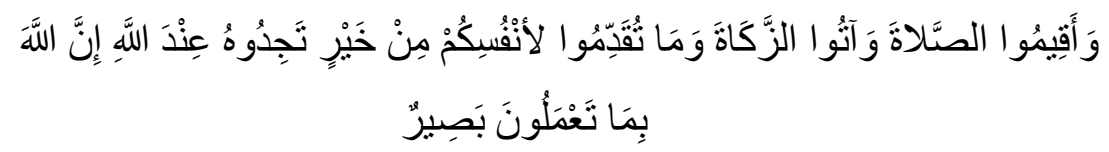

Artinya: "Dan dirikanlah shalat dan tunaikanlah zakat, dan kebaikan apa saja yang kamuusahakan bagi dirimu, tentu kamu akan mendapat pahala nya pada sisi Allah. Sesungguhnya Allah maha melihat apa-apa yang kamu kerjakan” (Q.S. Al-Baqarah:110).”

Dalil tentang zakat bukan hanya di dalam al-quran namun juga di dalam hadits terdapat banyak hadis tentang zakat diantaranya sabda Rasulullah shallallahu 'alaihi wasallam yang artinya, "Islam dibangun di atas lima perkara: bersaksi bahwa tidak ada tuhan kecuali Allah dan Muhammad adalah utusan-Nya; mendirikan salat; melaksanakan puasa (di bulan Ramadan); menunaikan zakat; dan berhaji ke Baitullah (bagi yang mampu)" (HR. Muslim).

Kewajiban zakat ini berdasarkan Ayat-ayat yang tegas dan hadis-hadis yang shahih dan kewajiban ini telah terlaksana dari generasi ke generasi Kita dapat kembali membuka lembaran sejarah bagaimana pendapat tentangnya dan penerapannya Sebagaimana yang telah terungkap dalam ajaran islam itu sediri. Oleh sebab itu jelaslah bahwa zakat itu bajib bagi kaum muslim dan para ulama juga berpendapat bahwa zakat tidak di wajibkan bagi non muslim karna zakat merupakan anggota tubuh islam yang sangat utama maka orang kafir tidak mungkin di minta untuk melengkapinya Serta bukan pula merupakan utang yang harus di penuhinya ketika masuk islam.

\footnotetext{
${ }^{4}$ Muhammad Abduh Tuasikal, Panduan Zakat Minimal 2.5\% (Yogyakarta: Rumaysho, 2020).
} 


\section{Zakat maal}

a. Pengertian zakat maal

Kata "mâl" berasal dari bahasa arab yang jamaknya Al-amwaal. Secara etimologis Al-maal dapat di artikan miring, condong, cenderung, atau segala sesuatu yang diinginkan sekali oleh manusia untuk dimiliki dan disimpannya. Sedangkan menurut syarat, mâl adalah segala sesuatu yang dapat dimiliki atau dikuasai dan dapat digunakan (dimanfaatkan) sebagaimana lazimnya. ${ }^{5}$ Zakat maal (harta), seperti emas, perak, binatang, tumbuh-tumbuhan dan barang perniagaan (barang dagangan)

b. Hukum zakat maal

Membayar zakat maal hukumnya wajib sama dengan zakat fitrah sendiri masuk dalam rukun islam yang keempat. Pelaksanaan zakat maal adalah mengeluarkan sebagian harta yang di miliki untuk di berikan kepada orang yang berhak menerimanya, baik di distribusikan secara mandiri maupun melalui panitia zakat, namun tidak semua ummat muslim berkewajiban mengeluarkan zakat maal. Syarat terkenanya kewajiban zakat maal di adalah:

1) Pemilik harta tidak memiliki utang jangka pendek yang harus dilunasi.

2) Kepemilikan sempurna

3) Harta tersebut dapat berkembang (produktif atau berpotensi produktif)

4) Harta tersebut mencapai nisab sesuai jenis hartanya.

5) Harta tersebut melewati haul.

\section{Orang Yang Berhak Menerima Zakat}

Zakat merupakan salah satu ibadah yang diperintahkan oleh Allah Swt. Kepada umat manusia, dengan tujuan dan sasaran yang jelas berdasarkan AlQur'an dan al-hadis, namun dalam prakteknya di tengah masyarakat, sering kali terjadi salah sasaran. sasaran zakat ditujukan kepada delapan asnaf yang terdiri dari,

\footnotetext{
${ }^{5}$ Ahmad Hadi Yasin, PANDUAN ZAKAT PRAKTIS (Jakarta: Ismail A. said, 2011).
} 
fakir dan miskin, amil, muallaf, memerdekakan budak (riqab), orang yang berutang (gharim), orang yang berjuang di jalan Allah (fi $<$ sabilillah), dan ibnu sabil. ${ }^{6}$ Sebagaimana telah disebutkan dalam QS. At-tawbah: 60

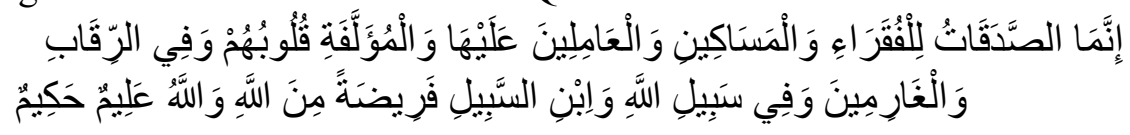

"Sesungguhnya zakat itu hanyalah untuk orang-orang fakir, orang miskin, amil zakat, yang dilunakkan hatinya (mualaf), untuk (memerdekakan) hamba sahaya, untuk (membebaskan) orang yang berhutang, untuk (yang berjihad) di jalan Allah dan untuk orang yang sedang dalam perjalanan, sebagai kewajiban dari Allah. Allah Maha Mengetahui, Mahabijaksana.”

Berikut golongan penerima zakat berdasarkan QS. At-tawbah ayat 60:

a. Fakir dan miskin

fakir dan miskin adalah golongan pertama dan kedua yang berhak menerima zakat, mereka itulah yang pertama di beri bagian harta zakat oleh Allah. Ini menunjukkan bahwa sasaran pertama zakat adalah hendak menghapuskan kemiskinan dan kemelaratan dalam masyarakat. (yusuf qordowi) Golongan fakir dan miskin adalah golongan yang harus di utamakan dalam penyaluran zakat karna dalam Al-Quran kedua golongan ini yang didahulukan.

b. Amil zakat

Amil zakat adalah golongan yang ketiga setelah fakir dan miskin yang berhak menerima zakat.

Amil Zakat harus memenuhi syarat sebagai berikut :

1. Beragama Islam

2. Mukallaf (berakal dan baligh)

3. Amanah

4. Memiliki ilmu pengetahuan tentang hukum -hukum zakat dan hal lain yang terkait dengan tugas amil zakat. ${ }^{7}$

\footnotetext{
${ }^{6}$ M.A. Samsul arifai S.A.B., "TUJUAN DAN SASARAN ZAKAT DALAM KONTEKS IBADAH DAN MUAMALAH," IBEF: Islamic Banking, Economic and Financial Journal Volume 1, Nomor 1, Desember (2020), h. 83-94, 1.1 (2020), 1-14 <http://journal.uinalauddin.ac.id/index.php/IBEF/article/view/19428>.

${ }^{7}$ BAZNAS BANYUASIN, "AMIL ZAKAT," Baznas Banyuasin

<https://baznas.banyuasinkab.go.id/amil-zakat/>.
} 
Amil zakat tidak di syaratkan harus miskin, karena amil zakat mendapat bagian zakat disebabkan hasil pekerjaannya atau sebagai upah dari hasil pekerjaannya. (Muhammad abduh tuasikal)

c. Muallafatuqulubuhum (orang yang ingin dilembutkan hatinya)

Muallaf adalah mereka yang baru masuk islam dan membutuhkan bantuan untuk menguatkan tauhid dan Syariah, muallaf terbagi dua muslim dan kafir. Mereka adalah pemimpin yang di taati dalam golongan mereka. Kafir di bagi lagi dalam dua golongan, golongan pertama adalah mereka yang di harapkan masuk islam, mereka di beri zakat supaya menambah keinginan dan hasratnya terhadap islam sehingga menjdi muslim yang seutuhnya. Golongan kedua adalah mereka yang ditakutkan akan berbuat jahat sehingga ia di berikan zakat untuk mencegah kejahtannya.

d. Riqab (Budak/Hamba Sahaya)

Budak/Hamba sahaya yang ingin memerdekakan dirinya. Pembebasan budak yang di maksud di sini adalah:

1) Pembebasan budak mukatab yaitu budak yang telah berjanji pada tuannya untuk memerdekakan dirinya dengan ketentuan melunasi pembayaran tertentu.

2) Pembebasan budak muslim

3) Pemebasan kaum muslim yang berada di tawanan orang kafir. ${ }^{8}$

e. Gharimin (orang yang terlilit utang)

Gharim adalah orang yang berutang, sulit untuk membayarnya para rahimahumullah telah membagi utang menjadi dua bagian utang untuk memenuhi kebutuhan dan untuk mendamaikan dua hubungan.

${ }^{8}$ Muhammad Abduh Tuasikal., Panduan Zakat Minimal 2,5\%, 1384. 
f. Sabilillah

Ulama dari dahulu sampai sekarang diantara mereka ada yang meluaskan arti sabilillah tidak hanya khusus pada jihad dan yang berhubugan dengannya, akan tetapi ditafsirkannya pada semua hal yang mencakup kemaslahatan, takarrub, dan perbuatan-perbuatan baik, sesuai dengan penerapan asal dari kalimat tersebut.

Menurut empat mazhab sabilillah adalah orang yang sukarela berperang untuk membela agama islam. Sedangkan di antara ulama yang meluaskan arti sabilillah seperti imam An-Nawawi, Asy-Syanqitiy, dan Qadi 'iyad, orang-orang yang berada di jalan Allah secara umum, baik yang berperang, bekerja di sekolahsekolah atau rumah sakit pengurus-pengurus masjid dan semua bentuk kemaslahatan umum ialah sabilillah.

g. Ibnu sabil

As-sabil secara bahasa berarti Ath-thariq atau jalan. Jumhur ulama mengkiaskan ibnu sabil dengan musafir, yaitu orang yang bepergian jauh dari satu daerah ke daerah lainnya yang bukan untuk kemaksiatan. sedang menurut Yusuf Qardawi tidak semua oraang yang melakukan perjalanan demi suatu kemaslahatan berhak menerima zakat walaupun perjalananya untuk suatu kemanfaatan tertentu.

Selain orang yang melakukan perjalanan anak yang terlantar juga termasuk ibnu sabil, gelandangan dijalanan dan mereka yang tidak memiliki rumah termasuk pula golongan ibnu sabil.

\section{Hikmah Zakat}

Hikmah zakat yang di maksudkan disini adalah kemanfaatan lahir dan batin baik bagi yang meneriam zakat maupun yang mengeluarkan zakat, dalam al-quran dan hadits di jumpai beberapa hikmah atas perintah zakat ini, diantaranya:

1. Menyempurnakan keislaman seorang hamba. Zakat merupakan bagian dari rukun islam. jadi apabila sesorang melakukanya maka hal itu menjadi salah 
satu penyempurna keislamannya. Tidak diragukan lagi hal ini menjadi tujuan yang sangat agung. Setiap muslim pasti selalu berusaha mendambakan agar keislamannya menjadi sempurna. ${ }^{9}$

2. Menjadikan masyarakat islam seperti keluarga besar (satu kesatuan). Zakat merupakan sarana bagi orang kaya untuk menolong orang miskin dan orang yang berkecukupan menolong orang yang kesulitan. Pada akhirnya setia puslim akan memandang muslim lainnya sebagai saudara. ${ }^{10}$ Allah Ta'ala berfirman:

$$
\text { وَأَحْبِنْ كَمَا أَحْسَنَ اللَّهُ إِلَيْنَ }
$$

"Dan bebuat baiklah (kepada orang lain) sebagaimana Allah berbuat baik kepada kamu” (QS. Qashash:77).

3. Zakat menjaga dan memelihara harta dari incaran pendosa seperti pencurian, pemaksaan dan perampasan. Dengan zakat sebagian kebutuhan orang miskin dapat terpenuhi, sehigga hal itu mejadi penghalang bagi mereka untuk melakukan dosa dan kedzaliman kepada orang kaya.

4. Zakat sebagai pertolongan bagi orang-orang fakir dan orang-orang yang membuthkan bantuan, zakat menjadi pendorong mereka untuk semangat bekerja ketika mereka mampu melakukannya dan dapat mendorog mereka meraih kehidupan yang layak.

5. Zakat menyucikan jiwa dari penyakit kikir dan akhlak tercela serta melatih seorang muslim untuk berakhlak mulia dan bersifat dermawan.

${ }^{9}$ Muhammad Abduh Tuasikal.

${ }^{10}$ Muhammad Abduh Tuasikal. 


\section{BAB III \\ PENUTUP}

\section{A. Kesimpulan}

1. Zakat berarti bersih, tumbuh, berkah dan terpuji, dalam pembahasan fikih istilah zakat di artikan sebagai sejumlah harta tertentu yang di wajibkan Allah untuk dikeluarkan dan di serahkan kepada orang yang berhak menerimanya.

2. Zakat terbagi dua yaitu zakat fitrah dan zakat maal. Adapun syarat zakat fitrah adalah Islam, merdeka, berkecukupan. Dan syarat zakat maal adalah
a. Pemilik harta tidak memiliki utang jangka pendek yang harus dilunasi.
b. Kepemilikan sempurna
c. Harta tersebut dapat berkembang (produktif atau berpotensi produktif)
d. Harta tersebut mencapai nisab sesuai jenis hartanya.
e. Harta tersebut melewati haul.

3. Adapun yang berhak menerima zakat adalah
a. Fakir dan miskin
b. Amil zakat
c. Muallafatuqulubbuhum
d. Budak/hamba sahaya
e. Ghorim
f. Fi sabbilillah
g. Ibnu sabil

4. Hikmah zakat fitrah adalah
a. Menyempurnakan keislaman seorang hamba.
b. Menjadikan masyarakat islam seperti keluarga besar.
c. Menjaga dan memelihara harta dari incaran pendosa. 
d. Sebagai pertolongan bagi orang fakir dan orang yang butuh bantuan.

e. Menyucikan jiwa dan melatih bersifat dermawan.

\section{B. Saran}

Demikianlah makalah ini di susun berdasarkan Al-Quran dan sunnah serta pemahaman para ulama akan tetapi penyusun makalah ini tak lain hanyalah manusia biasa banyak kelemahan dan kekhilafan sehingga diharapkan pendapat dan saran yang baik dan membangun dalam memperbaiki makalah ini. Dan penyusun menyarankan pada pembaca yang ingin memahami masalah zakat lebih dalam hendaklah juga membaca sumber lain yang lebih lengkap. Semoga makalah ini dapat diterima oleh khalayak umum sebagai sumber pengetahuan yang baik dan bernilai positif untuk penulis dan pembacanya. 


\section{DAFTAR PUSTAKA}

Ahmad Hadi Yasin, PANDUAN ZAKAT PRAKTIS (Jakarta: Ismail A. said, 2011)

BAZNAS BANYUASIN, “AMIL ZAKAT,” Baznas Banyuasin

$<$ https://baznas.banyuasinkab.go.id/amil-zakat/>

Kementrian Agama RI, Panduan Zakat Praktis (Jakarta, 2013)

Muhammad Abduh Tuasikal, Panduan Zakat Minimal 2.5\% (Yogyakarta:

Rumaysho, 2020)

Samsul arifai S.A.B., M.A., "TUJUAN DAN SASARAN ZAKAT DALAM

KONTEKS IBADAH DAN MUAMALAH,”IBEF: Islamic Banking,

Economic and Financial Journal Volume 1, Nomor 1, Desember (2020), $h$.

83-94, 1.1 (2020), 1-14<http://journal.uin-

alauddin.ac.id/index.php/IBEF/article/view/19428>

Tuasikal., Muhammad Abduh, Panduan Zakat Minimal 2,5\%, 1384

Yusuf Qordowi, Hukum Zakat (Bogor: PT. Pustaka Mizan, 1988) 